\title{
Input Subsidy Programs and Climate Smart Agriculture: Current Realities and Future Potential
}

\author{
Tom S. Jayne, Nicholas J. Sitko, Nicole M. Mason, and David Skole
}

\begin{abstract}
The achievement of Climate Smart Agriculture (CSA) goals in Africa will require widespread farmer adoption of practices and technologies that promote resilience and system-wide collective action to promote ex ante climate risk management activities and ex post coping strategies. Leveraging public sector resources is critical to achieve goals at scale. This study examines the scope for input subsidy programs (ISPs) to contribute to achieving CSA objectives in Africa. Available evidence to date suggests that in most cases ISPs have had either no effect on or have reduced SSA smallholders' use of potentially CSA practices. However, recent innovations in ISPs may promote some climate smart objectives by contributing to system-level ex-ante risk management. In particular, restricted voucher systems for improved seed types that utilize private sector distribution supply chains may prove capable of promoting CSA goals. Generally, moving from systems that prescribe a fixed input packet to a flexible system with a range of input choices holds promise, but fixed systems still hold some benefits. Conditional ISPs would require improved monitoring and compliance as well as defining practices with clearly measurable productivity benefits vis-à-vis CSA goals. The potential of ISPs to achieve widespread CSA benefits must address these challenges and be evaluated against benefits of investments in irrigation, physical infrastructure, and public agricultural research and extension, which may generate higher comprehensive social benefits.
\end{abstract}

\footnotetext{
T.S. Jayne $(\bowtie) \bullet$ N.J. Sitko $\bullet$ N.M. Mason

Department of Agricultural, Food and Resource Economics, Michigan State University,

East Lansing, MI, USA

e-mail: jayne@msu.edu; sitkoni1@msu.edu; masonn@msu.edu

D. Skole

Department of Forestry, Michigan State University, East Lansing, MI, USA

e-mail: skole@msu.edu
} 


\section{Introduction}

There is growing global recognition of the urgent need to identify and implement strategies that make food systems more resilient in the face of increasing climate variability. Nowhere is this more evident than in Sub-Saharan Africa. ${ }^{1}$ Because the majority of Africans' livelihoods and agrifood systems rely on rainfed farming, Africa is one of the world's regions most vulnerable to climate change. The Intergovernmental Panel on Climate Change concluded that "climate change is expected to have widespread impacts on African society and Africans' interaction with the natural environment" (IPCC 2014, p. 812).

Climate smart agriculture (CSA) has emerged as an approach to enhance the resilience of farm systems to the effects of climate change. CSA is defined by three principle objectives (FAO 2013):

1. sustainably increasing agricultural productivity and incomes;

2. adapting and building resilience to climate change, and;

3. reducing and/or removing greenhouse gases emissions, where possible.

In Africa and other predominantly agrarian regions, there is particular interest in identifying strategies to encourage farmers to adopt practices and technologies that enable more resilient, sustainable and productive farms, while at the same time identifying system-wide collective action to promote a wide range of ex ante risk management activities and ex post coping strategies. Given the scope and scale of these requirements, leveraging public sector resources is critical.

Input subsidy programs (ISPs) provide a potentially useful means to encourage system-wide coordination and farmer behaviours that raise agricultural productivity and contribute to resilience objectives in Africa, while potentially mitigating the agricultural sector's contribution to GHG emissions. ISPs vary in their distribution modalities and targeting requirements, but generally share the common attributes of providing inorganic fertilizer, and in some countries, improved seeds, to farmers at below-market prices. Many African governments currently devote a large share of their agricultural sector and national budgets to ISPs. The region spends just over US\$1.0 billion each year on ISPs (Jayne and Rashid 2013; Jayne et al. forthcoming). A major challenge to enabling ISPs to promote CSA outcomes stems from the major opportunity costs they entail in terms of foregone public spending on other core CSA investments such as irrigation, agricultural R\&D, and extension services that could potentially promote CSA practices more effectively per dollar invested than ISPs. However, there is clearly scope for market-smart ISPs to improve smallholder farmers' access to climate smart technologies and overall resilience. This paper assesses the feasibility of leveraging public investments in ISPs to promote adoption of CSA practices and technologies by African farmers.

The paper is organized as follows. Section 2 begins by defining CSA in the context of African smallholder farming systems. Section 3 briefly examines the range

${ }^{1}$ Hereafter "Africa". 


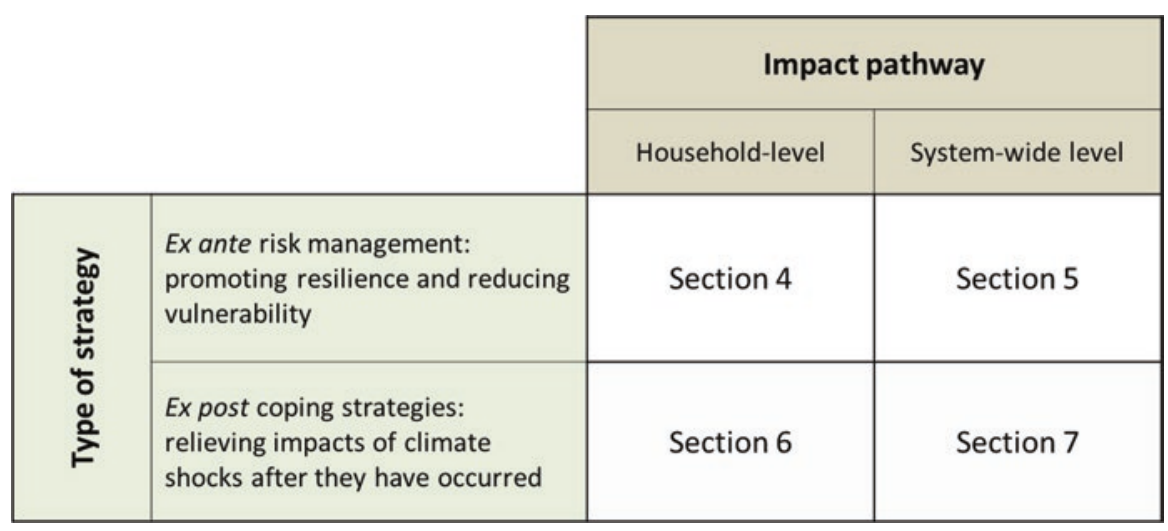

Fig. 1 Various dimensions of how input subsidy programs might contribute to climate smart agriculture

of ISP implementation modalities and approaches in Africa. In Sects. 4, 5, 6, and 7, we adopt the $2 \times 2$ matrix framework of Lipper and Zilberman (forthcoming) to consider how ISPs may promote resilience of farming systems in the face of climate shocks through ex ante risk management strategies, and how ISPs might be designed to mitigate the effects of climate shocks through ex post coping strategies. These impact pathways are evaluated across household/farm level and responses at the system-wide/government level (Fig. 1). Section 4 focuses on household-level ex ante risk management strategies. Section 5 focuses on system-wide ex ante risk management strategies. Section 6 examines the ability of ISPs to support householdlevel ex post responses to climate shocks. Section 7 examines system-wide ex post strategies. Section 8 summarizes our findings and discusses potential implications for ISP policies and programs.

\section{Defining Climate Smart Agriculture}

Although not clearly defined in the academic literature, the term "climate smart agriculture" (CSA) has gained prominence as an emergent agricultural development paradigm (Engel and Muller 2016). The UN Food and Agricultural Organization (FAO), the principle architect of CSA, defines it as an approach that "sustainably increases productivity and resilience (adaptation), reduces/removes GHGs (mitigation), and enhances achievement of national food security and development goals" (FAO 2010, p. ii; FAO 2013). CSA is therefore largely defined by its intended outcomes rather than by a set of specific practices or approaches (Kaczan et al. 2013).

CSA shares many objectives and guiding principles with green economy and sustainable development approaches, including a prioritization of food security and a desire to preserve natural resources. It is also closely linked to the concept of sustainable intensification (SI) (FAO 2013; Campbell et al. 2014). In many cases, SI 
constitutes a subset of practices that are potentially climate smart under certain current and future climatic conditions. As the FAO Sourcebook on CSA (2013) states, CSA extends these concepts through "a more forward looking dimension, more concern about future potential changes and the need to be prepared for them" (p. 30). Thus, CSA is not a set of new agricultural practices or a new agricultural system. Instead, it is understood as a new approach to guide necessary changes to agricultural systems in order to jointly address challenges of food security and climate change (Lipper et al. 2014; Branca et al. 2011; FAO 2013; Grainger-Jones 2011).

Proponents of CSA emphasize several hallmarks of its approach. First, CSA focuses on risks throughout the food system, with a particular emphasis placed on ex ante risks to smallholders resulting from the interaction of changing climate with existing livelihood vulnerabilities (McCarthy et al. 2011; Meinzen-Dick et al. 2013; Grainger-Jones 2011; World Bank 2011). Second, elevating the visibility of emergent risks that smallholders face offers opportunities to focus strategically on practices and technologies that offer multiple benefits in the areas of climate change adaptation, mitigation, and food security. Finally, by linking climate change adaptation and mitigation to smallholder production practices, CSA creates opportunities to link smallholders to previously unavailable sources of support, including climate finance (Meinzen-Dick et al. 2013; Grainger-Jones 2011).

There are a number of SI practices that are often linked to CSA objectives. These include: minimum soil disturbance (zero or minimum tillage); crop rotation and intercropping, particularly with legumes; mulching; crop residue retention; cover cropping; agro-forestry; water management, including irrigation and drainage; integrated soil nutrient management, including efficient use of mineral fertilizer in combination with organic sources; and use of high quality, well-adapted seed varieties. In many cases, these are not new practices, but adoption rates in Africa remain low or sub-optimal (Branca et al. 2011). For the purpose of this paper we will refer to these practices collectively as SI practices, recognizing that they are also closely linked to CSA objectives.

\section{ISP Implementation Modalities and CSA in Africa}

Following the implementation of structural adjustment programs, spending on ISPs in Africa declined substantially. Yet, in the wake of the global food price spike of 2007/2008 and based on the apparent success of Malawi's subsidy program, Africa has seen a resurgence of ISPs. According to Jayne and Rashid (2013), by 2011 ten African countries spent over $\$ 1.05$ billion on ISPs, or roughly $28.6 \%$ of these countries' total public agricultural expenditures.

The majority of new ISPs in Africa focus on subsidizing improved seed and inorganic fertilizers for staple cereal production by smallholder farmers. A few also provide subsidies for small grains and legumes. Variations in ISP design are most notable in terms of: (i) the extent to which the private sector is utilized to distribute 
inputs, (ii) the range of inputs available to farmers, and (iii) the socio-economic characteristics of the target beneficiaries.

The distribution system and flexibility of input choices for farmers have important implications for their climate smartness. Most ISPs utilize closed voucher systems, where farmers redeem coupons for a prescribed input packet from government-run or designated outlets, or direct delivery systems, where government or contractors deliver prescribed input packets. These types of systems tend to limit farmers' choice of inputs, are rarely attentive to agro-ecological and livelihood variations across space, crowd out private sector participation, and are frequently characterized by elite capture of inputs (Ricker-Gilbert et al. 2011; Mason and Ricker-Gilbert 2013; Pan and Christiaensen 2012; Mason et al. 2013; Lunduka et al. 2013). Such systems, like those in Zambia and Malawi, tend to undermine the development of private sector market channels, encourage mono-cropping and incentivize the production of crops in regions where they are poorly suited (Mason et al. 2013; Lunduka et al. 2013; Levine 2015). These outcomes are clearly contrary to the goals of CSA.

Recently, however, countries have begun to take tentative steps toward implementing more flexible, open voucher systems for ISPs in order to address some of these shortcomings. In Zambia for example, an electronic voucher system was piloted on a limited scale in 2015/2016, where farmers redeem vouchers with registered private sector dealers for a wide range of inputs. These systems can lower ISPs fiscal cost to government, encourage private investments in input supply systems and extension, and allow farmers to choose appropriate inputs (Sitko et al. 2012). These outcomes are decidedly more climate smart than the dominant model.

However, trade-offs exist between the relative flexibility of an ISP and the promotion of particular technologies or farm practices that may be climate smart. For example, open voucher systems may be less effective for promoting the adoption of seed varieties that are drought, heat, or flood tolerant, as there is no way to ensure that farmers will choose these seed types with a completely open voucher. More closed voucher systems may be more appropriate for encouraging the use of particular technologies. Similarly, closed voucher programs may help private seed firms to forecast demand for seed types, such as legume seeds, which is notoriously difficult to predict from year to year. By providing clarity on the effective demand for particular inputs, closed vouchers systems may prove useful to help overcome input supply constraints that hinder the adoption of certain potential SI and CSA practices, such as legume intercropping and rotations.

\section{Can ISPs Promote Household-Level Ex Ante Risk Management?}

Having reviewed in general terms how ISPs are implemented and potential linkages to SI and CSA practices, we now examine specific strategies that may foster more climate resilient and productive smallholder farm systems. The sorts of SI and CSA 
management practices we examine include tillage method, intercropping and rotations, the use of manures and residue retention, and agro-forestry, inter alia. More broadly, we explore the potential relationship between ISPs and practices that can potentially improve soil characteristics and stabilize yields in the context of climate variability.

\subsection{Review of Evidence to Date}

The evidence base remains thin but the weight of the available evidence suggests that ISPs have had either no effect on or have reduced African smallholders' use of CSA practices. Empirical evidence across many case studies shows mixed results for many CSA practices considered. In addition, studies show the difficulties posed by delivery mechanisms that provide inputs too late for effective and efficient use by farmers. Finally, the absence of robust agricultural extension services in many African countries makes the diffusion and implementation of CSA practices even more challenging.

More specifically, evidence suggests that ISPs did not affect Ghanaian farmers' investment in soil and water conservation, broadly defined (Vondolia et al. 2012), nor did they affect Malawian or Zambian smallholders' use of manure (Holden and Lunduka 2010, 2012; Levine 2015). And while Malawi's ISP had no statistically significant effect on intercropping (Holden and Lunduka 2010), Zambia's ISP has reduced intercropping in general, but not intercropping involving legumes (Levine 2015). Moreover, Zambia's ISP has negatively affected crop rotation and fallowing (ibid; Mason et al. 2013). The program has contributed to continuous cultivation of mono-cropped maize over time and within seasons, which leave smallholders more vulnerable to climate shocks - the antithesis of CSA. ISPs may increase maize yields in the short run except during extreme weather conditions (see Holden and Lunduka 2010; Mason et al. 2013; Chibwana et al. 2014; Mason et al. 2015; among many others). However, if results similar to Zambia are obtained elsewhere, these yield gains could be coming at the cost of lower soil organic matter and higher soil acidity, both of which will result in lower yields and fertilizer use efficiency in the medium to long run (Marenya and Barrett 2009; Burke 2012).

Empirical evidence on the effects of ISPs on crop diversification is mixed. For example, while Chibwana et al. (2012) and Mason et al. (2013) find that ISPs in Malawi and Zambia, respectively, incentivize households to devote a greater share of their cropped area to maize, other studies from Malawi suggest the opposite (Holden and Lunduka 2010; Karamba 2013) or that ISPs have no statistically significant effect on crop diversification (Karamba 2013). Most likely, the effects of ISPs depend on the range of inputs provided. ISPs that focus less on a specific crop and support a broader range of alternative crops, in particular legumes that add biomass and moisture retention to soil, may generate better outcomes with respect to crop diversification and soil fertility, responsiveness of crops to inorganic fertilizer and other benefits (Snapp et al. 2010). 
While ISPs may contribute to sustainable productivity growth by maximizing fertilizer to crop output efficiency, their track record has been disappointing. Jayne et al. (forthcoming) conclude that most African governments to date have focused more on increasing African farmers' use of fertilizer than on providing support for its efficient use.

Another feature of many ISPs that is decidedly not climate smart is perennial late delivery of subsidized fertilizer and seeds to beneficiary farmers (Xu et al. 2009; Lunduka et al. 2013; Mason et al. 2013; Namonje-Kapembwa et al. 2015). Late delivery is particularly common when ISP inputs are disseminated through dedicated ISP distribution systems that largely sideline existing input distribution networks. This is how fertilizer for Malawi's ISP and both fertilizer and seed for Zambia's ISP were distributed until 2014/15 and 2015/16, respectively, when each country started piloting agrodealer-based voucher redemption systems (Logistics Unit 2015; ZMAL 2015a; b). Late delivery of ISP inputs results in late planting and/or late fertilizer application, reducing yields and leaving beneficiary households more vulnerable to climate shocks (Xu et al. 2009; Namonje-Kapembwa et al. 2015; Arslan et al. 2015).

Most public agricultural extension systems are seriously under-provisioned to perform their multiple mandates of providing new management advice to farmers, learning from their efforts and difficulties of implementation and liaising with adaptive research systems to generate and disseminate new productive and sustainable practices, including SI practices. Some African public extensions are virtually defunct. Therefore, it should not be surprising that despite heavy spending on ISPs, their impacts on crop yields have been smaller than anticipated (ibid). In Zambia and Malawi, for example, a one-kilogram increase in subsidized fertilizer raises smallholder households' maize output by an average of only $1.88 \mathrm{~kg}$ and $1.65 \mathrm{~kg}$, respectively (Mason et al. 2013; Ricker-Gilbert et al. 2011). This low crop yield response to fertilizer is a major reason for the relatively low benefit-cost ratios of the ISPs in Malawi (1.08) and Zambia (0.92) (Jayne et al. 2017).

In response to some of these limitations, many ISPs are currently transforming to more flexible, private-sector, inclusive systems. This creates possibilities for ISPs to be restructured in ways that incentivize farmers to adopt particular SI practices and also bring about system-wide changes that promote resilience. The remainder of this section examines this potential of ISPs, however the discussion is largely conjectural given the limited evidence that ISPs as implemented to date have achieved such benefits.

\subsection{Looking Forward: Can ISPs Contribute to Climate Smart Farm Management Practices?}

A handful of ex ante analyses have explored how ISPs might compare to other programs to promote farmers' use of practices that may be climate smart. For example, Marenya et al. (2012) use 30-year crop simulation models for maize, rice, and sorghum calibrated for several districts in Kenya, Malawi, and Uganda to compare 
changes in the net present value (NPV) of adopting various soil fertility management (SFM) strategies under two sets of policy regimes: a 50\% fertilizer subsidy and carbon credits priced at $\$ 4, \$ 8$, or $\$ 12$ per metric ton of carbon sequestered in the soil. The SFM strategies considered include various combinations of inorganic (N) fertilizer, animal manure, and crop residue retention - practices that may be 'climate smart' in some contexts. Their results suggest that carbon credits, especially when priced at $\$ 8$ or $\$ 12 / \mathrm{mt}$, produce larger NPV increases than the 50\% fertilizer subsidy. While carbon markets are virtually non-existent in Africa, this analysis suggests monetary incentives play an important role in stimulating adoption of climate smart practices. This leaves room for ISPs to deliver monetary incentives to such ends. Yet, this in turn requires that extension systems are capable of delivering appropriate management information and that adoption is effectively monitored, which seems very challenging.

In later work, Marenya et al. (2014) use choice experiments to measure Malawian smallholder farmers' preferences for various hypothetical policy incentives to adopt soil conservation practices, namely minimum tillage with legume intercropping: cash payments, two different types of index-based crop insurance contracts, and fertilizer subsidies. ${ }^{2}$ Results suggest that most farmers preferred fertilizer subsidies to cash payments or crop insurance. In addition, farmers generally preferred cash payments to crop insurance, even when the expected payout from the crop insurance was higher than the cash payment. We must be careful, however, in generalizing these results, as they are specific to the choice sets used in the experiments. For example, the expressed preference of fertilizer subsidy over cash payments is likely driven by the fact that cash payment options (ranging from MK 800 to MK 2000) were lower compared to fertilizer subsidy (MK 2000) because of the expected yield gains with fertilizer. Even still, both cases suggest that under the right conditions some combination of conditional subsidy or conditional cash payment can incentivize adoption of farm management practices. Whether or not this leads to a permanent behavioral change, or whether public entities are capable of monitoring adherence to the conditions, remains an open question.

Finally, there is the question about whether raising crop productivity through inorganic fertilizer use might reduce the rate at which forests are converted into farmland and therefore reduce the agricultural sector's contribution to GHG emissions. Recent evidence has begun to question the logic that agricultural productivity growth can arrest rapid farm area expansion and thus conserve the world's forests and grasslands (Hertel 2011; Robertson and Swinton 2005; Byerlee et al. 2014). Instead, a generally positive area response to improved profit incentives is likely to create new pressures for further area expansion and conversion of forest and grasslands to farmland. Policy incentives could play a potential role here. In theory, ISPs could be structured in such a way as to oblige beneficiaries to reduce or maintain the amount of area under cultivation. However, it is not clear whether such

\footnotetext{
${ }^{2}$ Farmers also had the option to decline the soil conservation incentives in favor of continuing 'traditional' practices, which in the context of the choice experiments were defined as not using chemical fertilizer or the soil conservation practices.
} 
rules would impose unreasonable demands on food insecure rural households or whether they could be adequately monitored or enforced.

In summary, while ISPs can be theoretically structured in ways that promote farm-level management changes, the oversight, enforcement, and extension costs needed to make this work are high, and may increase the already substantial opportunity costs of large public expenditures on ISPs.

\subsection{How Confident Are We That We Know Which Farming Practices Contribute to CSA and SI?}

As the development community understandably pushes hard to make progress in helping African farmers, there are major risks of overgeneralization about what kinds of farming practices really contribute to ex ante risk management and ex post coping strategies. Africa is heterogeneous with respect to its climate conditions, soil types, market access conditions, and factor price ratios. Some parts of Africa are still land abundant; labor and capital may be binding constraints in such areas. Other agricultural areas of Africa are densely populated, facing land pressures and rising land prices. In some of these areas, labor is relatively abundant and hence laborintensive CSA practices may hold some potential to be scaled-up and incentivized through ISPs. However, in areas with good market access conditions and proximity to urban areas, economic transformation processes are bidding up labor wages and making it difficult for farmers to adopt labor-intensive CSA practices unless they also provide high returns to labor. The heterogeneous conditions of farming systems in Africa warrant great caution against overgeneralization in promoting technologies through ISPs or on their own based on blanket recommendations across wide domains.

As an example, minimizing soil disturbance through no or minimum tillage $(\mathrm{MT})^{3}$ strategies are frequently promoted in Africa as a means to mitigate soil erosion, increase soil water retention capacity, and to slow the rate of soil organic carbon (SOC) decomposition, and thus achieve yield growth and stability (Branca et al. 2011; Chivenge et al. 2007). However, yield and soil quality effects of MT practices vary substantially depending on soil type and association of MT with other land management practices, namely crop residue retention and incorporation. Several studies have shown that MT practices lead to an accumulation of SOC in the surface layers of soil $(0-10 \mathrm{~cm})$, rather than in the root zone (Sisti et al. 2004; Chivenge et al. 2007; Carter and Rennie 1982; Hernanz et al. 2002; Doran 1980). Carter and Rennie (1982) find that microbial biomass and potential mineralizable carbon and nitrogen are high in surface soils where MT is practiced. Conversely, these soil properties are higher in lower soil depths when conventional tillage (CT) is applied. The magnitude and location of the SOC pool are important for yield growth and

\footnotetext{
${ }^{3}$ In this section we present evidence on both zero and minimum tillage methods, which we will refer to broadly as minimum tillage (MT).
} 
stabilization. As Lal (2006) shows, every $1 \mathrm{mt} / \mathrm{ha}$ increase in the SOC pool in the root zone is associated with a $30-300 \mathrm{~kg} / \mathrm{ha}$ increase in maize yields and a $10-50 \mathrm{~kg}$ / ha increase in rice yields. Improving SOC pool in the root zone can simultaneously enhance soil's water retention capacity (Mbagwu 1991; Fernández-Ugalde et al. 2009), increase its cation exchange capacity, and thus nutrient retention (Carter et al. 1992), and improve soil aggregation and susceptibility to erosion (Lal 2006; Paul et al. 2013). Thus, further development of MT technologies may be needed to achieve its potential benefits.

Another potential limitation of MT is that without associated investments in crop residue retention and/or crop rotation, fields tilled using MT frequently experience no yield improvement (Hernanz et al. 2002) or in some cases a dramatic drop in yield relative to CT (Rusinamhodzi et al. 2011; Raimbault and Vyn 1991; Paul et al. 2013). When MT practices are applied in conjunction with crop residue retention, legume rotation, and/or nitrogen fertilizer application, the yield effects of MT tend to be higher than those achieved through CT, but again this is highly dependent on prevailing agro-ecological conditions (Raimbault and Vyn 1991; Govaerts et al. 2005; Dalal et al. 1991; Triplett et al. 1968).

As discussed in Section 3, ISPs in the region are not designed to cope with the high level of regional and farm level heterogeneity in input needs and management requirements. Significant region-specific modifications in the composition of ISP inputsm coupled with region-specific farm management promotion strategies will be required for ISPs to contribute meaningfully to CSA goals, which in turn implies significant modification in the logistical design, implementation and cost of ISPs.

A more obvious way in which ISPs can influence overall productivity is through the injection of greater levels of nitrogen $(\mathrm{N})$ into African soils, where nitrogen is often the limiting nutrient factor (Snapp et al. 2010). Rusinamhodzi et al. (2011) in their summary of evidence on conservation agriculture shows that in $73 \%$ of the field studies, high levels of nitrogen fertilizer were required to achieve improved yields under these practices. However, recent advances in soil science and agronomy research show that massive nitrogen $(\mathrm{N})$ injections may not be economically feasible for farmers or be social welfare raising without farmer adoption of complementary soil management practices that allow $\mathrm{N}$ to be efficiently utilized by plants (Snyder et al. 2009). Thus, the challenge for large-scale programs, such as ISPs, is promoting carbon management practices together with nitrogen to achieve high nitrogen efficiency (Tittonell and Giller 2013). Paul et al. (2013) demonstrate that without sufficient biomass production (often stimulated by inorganic fertilizer application) SI practices of MT and residue retention do not have an effect on yield stability or SOC. Thus, an ongoing challenge is maintaining a large enough $\mathrm{N}$ pool in soils containing little organic carbon, which increases $\mathrm{N}$ leaching and gaseous loss pathways, adversely affecting CSA goals (Drinkwater and Snapp 2007). Unfortunately, large-scale efforts to promote SI practices that build up soil organic carbon are largely absent from government programs, are largely untested over the wide range of soil types and agro-ecologies found in the region, and are sometimes discounted by some as not being viable from the standpoint of low-resource farmers. 
These several examples underscore the lack of consensus within the crop science community about what viable CSA and SI packages appropriate for heterogeneous smallholder agricultural systems should look like. In addition, there is a great deal of uncertainty over how climate will change in the region over the coming decades (Powlson et al. 2016). For these reasons, we conclude that African governments and the development community need an improved empirical evidence base that establishes the practices that actually promote CSA and SI objectives under the wide range of diverse and uncertain farming conditions found in the region. A precondition for making progress on this front is much greater public expenditure on agricultural $\mathrm{R} \& \mathrm{D}$ and adaptive research across the various economic/biophysical micro-climates. While necessary, increased public funding to agricultural R\&D is not sufficient. But without a better evidence base on how practices perform under various conditions, the risk is that ISPs may be misguided in choosing which practices to promote.

\section{Can ISPs Promote System-Wide Ex Ante Risk Management?}

This section examines the potential of ISPs to encourage system-wide changes in agricultural value chains that promote resilience to risks associated with climate variability. Due to their scale, ISPs may have capacity to influence the broader systems within which farmers operate and thereby influence farmer behavior both directly as well as indirectly through system-wide changes. We identify three potential areas where these system-wide effects are most evident.

\subsection{Potential Opportunities}

First, as mentioned earlier, by expanding and stabilizing the demand for specified input types and quantities, ISPs can potentially help to overcome some of the persistent risks to commercial legume seed multiplication in the region. Ensuring adequate supplies of these seeds on the market is critical to achieving crop diversification, organic nitrogen fixation, and rotations. However, this potential benefit is mitigated by the trend, among donors and governments, to move toward more open voucher systems. Thus, in many ways there are important trade-offs to consider when promoting particular ISP distribution modalities. While open vouchers are desirable from a farmer choice perspective, restricted-choice vouchers for particular inputs, such as legume seeds, may be necessary to support system-wide improvements in legume seed supply chains. Restricted-choice vouchers may be justified in some instances where there are major beneficial externalities associated with promoting certain inputs and where the social benefits of doing so may greatly outweigh the short-term financial benefits from the perspective of individual farmers. The two 
approaches may be combined; for example, farmers could be provided an open voucher in addition to a restricted-choice voucher for legume seed. Similar systemwide benefits may accrue by using ISPs to create farmer demand for specific drought-tolerant seed varieties or soil amendments such as lime or inoculants, which are currently not widely used by farmers.

A second way in which ISPs may promote system-wide CSA resilience is through promoting "market-smart" private investments, which could increase private investments in input supply chains and extension services. By encouraging private sector input supply chain development, market-friendly ISPs can foster improved input access conditions for farmers, thus over time making them less dependent on public input supply systems. Private input systems are potentially less prone than public systems to delivery challenges associated with logistical and financial constraints (Jayne and Rashid 2013). There is clear potential for ISPs to promote system-wide investments that are both climate-smart and market-smart and synergistic in their promotion of community resilience to climate variability.

Finally, the move toward digital platforms for delivering ISPs, such as electronic vouchers ('e-vouchers'), create opportunities to use ISPs as delivery mechanisms for other sorts of products, such as weather indexed insurance. This requires that ISP farmer registries collect a wide range of information on beneficiaries, including geographic location and bank information. With this sort of information, ISPs can defray the screening costs of identifying farmers and managing insurance pay-outs when necessary.

\subsection{Potential Challenges}

Unfortunately, some aspects of ISPs may work against climate change mitigation even as they promote resilience objectives. ISPs increase the quantities of fertilizer manufactured and used in the agricultural production process (holding all other factors constant) and therefore ISP proposals that include increased fertilizer use must account for the additional GHG emissions. Inorganic fertilizer use contributes to GHG emissions both through the soil chemical and biological processes and through the production of synthetic fertilizer. According to a recent estimate, $56 \%$ of global non-carbon dioxide GHG emissions occur from agricultural production, and roughly $12 \%$ of agricultural GHG emissions occur from fertilizer use (IPCC 2014). The additional contribution to GHG emissions caused by the manufacturing of synthetic fertilizer is also significant (see Appendix 1). Thus, the net impact of ISPs on GHG emissions will depend on the effectiveness with which ISPs can be used to promote adoption of CSA practices that raise soil organic carbon, sequester carbon and depress the rate of forest conversion to farmland and offset the adverse effects of increased fertilizer use on GHG emissions. The empirical evidence on these issues is weak and more detailed research is needed. Appendix 1 provides some empirical estimates of the increased GHG emissions caused from additional use of synthetic fertilizers.

Moreover, there is the issue of opportunity costs. Nationwide ISPs tend to be expensive, and they can bid away scarce public funds that could otherwise be used to 
buffer communities from the effects of climate variability (e.g., irrigation, agricultural research and extension systems, weather insurance, etc.) or to support ex post coping responses (e.g., disaster relief programs). In Africa, where irrigation only accounts for $4 \%$ of arable land (You et al. 2012) and where there is huge unmet potential for irrigation expansion, ISPs would seemingly compete against public investment in water control and other ex ante risk management strategies. Future research is again needed to determine whether smart ISPs may be structured in ways that leverage private sector investments in CSA inputs and services and produce benefits that outweight those generated from other proven types of public investments in agriculture.

\section{Can ISPs Promote Household-Level Ex Post Coping Mechanisms?}

There may be limited potential for ISPs' ability to improve the ex post capacity of farm households to cope with shocks. Expenditures on ISPs occur before growing season weather outcomes are known. The greatest productivity boost from ISPs occurs in favorable weather years, and vulnerability to climate shocks is quite low during these periods. Vulnerability is of course greatest in extreme weather years. Unfortunately, fertilizer application typically contributes little to crop production growth during such years, and does nothing to stabilize crop yields in the face of extreme weather conditions. This inverse temporal correlation between years of great vulnerability to climate shocks and the payoffs from fertilizer application suggest that ISPs may have limited potential as ex post coping mechanisms at least for the period of time until the next harvest, generally 6-9 months later.

However, ISPs are frequently scaled-up in the year following a severe weather event as part of drought-recovery strategies. In such cases, ISPs act as tools to support smallholder households to acquire improved inputs and reengage in production following a severe contraction in farm income, and to potentially re-stock depleted resources that were expended during the crisis to smooth consumption. ISPs can also theoretically be used to help farmers replant crops that failed to survive due to late or false onset rains. Yet, in both cases this would require considerable budgetary flexibility and rapid implementation capacity on the part of governments. In addition, because of the annual crop production cycle characterizing most of the region, it may take time at least 6-9 months after a harvest failure before ISPs could contribute benefits to recipients in the form expanded crop output in the next season.

\section{Can ISPs Promote System-Wide Ex Post Coping Potential?}

In their current form, ISPs tend to be costly and therefore compete directly for scarce public sector resources with other CSA risk coping and response strategies, such as disaster risk management plans, rapid repair of damaged infrastructure, emergency feeding, etc. However, ISPs that increase access to weather insurance 
may help farmers avoid some forms of asset and resource depletion common after a weather shock. In addition, well-targeted ISPs may enable farmers to recover more quickly following extreme weather events. In these ways, ISPs do offer some potential avenues for timely response mechanisms following adverse weather shocks.

\section{Summary and Implications for ISPs}

In almost all countries where they have been implemented, ISPs have clearly promoted national grain production, at least in the years they were implemented. ISPs have a more checkered track record in terms of their impact on farm-level productivity, commercial input market development, and farm management behaviors that promote SI. Longstanding efforts to encourage policy makers to use "market smart" criteria have been disappointing, which has impeded the benefit-cost ratios of ISPs (Jayne and Rashid 2013; Jayne et al. 2017). It may be unrealistic at least in the near future to expect that political economy issues that have impeded efforts to make ISPs more effective can be easily overcome. But given that ISPs are likely to continue, and often account for a large share of public expenditures to agriculture, it may be worth the effort to encourage ISP reforms in ways that contribute to SI practices and CSA objectives.

This study has considered potential avenues of ISP impact on CSA objectives in terms of a time dimension - ex ante risk management strategies vs. ex post coping strategies - and at different levels of intervention - household-level behavioral change vs. system-wide changes. Using this conceptual lens we find that ISPs hold some potential to influence farmer behavior with respect to ex ante risk management strategies, such as the adoption of sustainable land management techniques, private investment in small-scale irrigation, use of drought-, heat-, and salineresistant crop varieties, use of hardier livestock breeds, and diversifying land and labor activities. Achieving these ends through ISPs is highly dependent on the existence of coordinated investments in both public extension services and research and development, along with monitoring systems. However, the cost of each component will require much greater public budgets devoted to agriculture to achieve the complementary approach needed.

Where ISPs may provide even greater opportunities to promote CSA objectives is through supporting ex ante risk management strategies at the system-wide level. Welldesigned ISPs may improve seed system performance for legumes and other improved varieties, as well as serving to link farmers to insurance systems. However, trade-offs exist between market development objectives of new ISPs and some of the systemwide constraints to CSA, such as legume seed supply constraints. For ISPs to improve legume seed supplies or access to particular climate improved seed varieties they may need to promote these through restricted-choice vouchers, in addition to or instead of the flexible vouchers being widely promoted in the region. Managing these trade-offs is important for achieving greater system wide benefits through ISPs. 
ISP's ability to improve household-level ex post coping mechanisms will likely be through support of post-disaster asset accumulation and reengagement with productive agriculture. Yet these outcomes, again, depend on effective public sector performance, particularly in terms of targeting the most affected households and regions.

In summary, ISPs may serve several catalytic functions at a system-level, which can support CSA objectives. However, ISPs can achieve little without the sorts of coordinated public and private investments in areas such as site specific adaptive research and extension, which are necessary to turn potential CSA practices into profitable and adoptable farm management strategies. Indeed, it is currently not possible to point to many, if any, new practices appropriate for smallholder African systems that are tried, tested, and can be confidently promoted as practices that promote CSA, are profitable, and feasible for farmers to adopt. Promoting certain technologies prematurely will lead to high levels of dis-adoption, disillusionment, and difficulties in getting farmers to participate in future programs.

Based on this analysis we propose the following as potential focal areas for improving the climate "smartness" of ISPs in Africa:

- Support greater concentration of ISPs on legume and climate improved cereal crops: Many ISPs currently focus primarily on staple cereal crops and inorganic fertilizers. For ISPs to have a more system-wide effect on cropping systems and management practices, seed system constraints for other crops must be addressed. ISPs can serve a catalytic role in this respect.

- Develop detailed farm registries for ISP beneficiaries: Detailed registries, that include geo-spatial information, are necessary to delivery support services such as weather insurance to farmers and to track adherence to targeting criteria.

- Explore the potential for using ISPs to overcome CSA farm management adoption constraints, bearing in mind that:

There is limited consensus on what practices are most effective for heterogeneous smallholder systems, and;

Extension advice and monitoring capacity remains very thin in most of Africa.

- Support systems to improve timing of input distribution through ISPs: ISPs chronically deliver fertilizer late (Xu et al. 2009; Namonje et al. 2015; Snapp et al. 2014). Late delivery reduces yields and crop response to fertilizer. This unfavorably affects the ratio of crop output to GHG emissions.

- Improve targeting capacity of ISPs: ISPs must more effectively target farmers who can use fertilizer profitably but are not already using it (or using it well below levels considered to be profit-maximizing). This will reduce crowding out of commercial demand and contribute to increased fertilizer use. In addition, effective targeting following a disaster can help support ISPs to support ex post household recovery efforts.

- Use extension systems and information and communications technologies (ICTs) to show farmers how the use of fertilizer from ISPs and/or commercially obtained 
fertilizer can become more profitable when complementary SI/CSA practices are adopted.

- Promote more secure land tenure/property rights (e.g., through registration or land certification): land tenure security is important for encouraging the adoption of SI/CSA practices that improve productivity, sustainable land management, and increased use of commercially purchased fertilizer (Lawry et al. 2014; Sitko et al. 2014). Efforts to promote secure land tenure rights are a complement, not necessarily a substitute, for ISPs in promoting CSA, but the cost-effectiveness of both may be different and justify different levels of budget support.

\subsection{Unresolved Issues for Future Research}

Key knowledge gaps include understanding why farmers are not adopting CSA practices or are subsequently dis-adopting them (which could then point to potential interventions to overcome these constraints); determining which practices are profitable for whom and under what conditions; understanding the interactions between CSA practices and ISP inputs (e.g., do selected CSA practices increase fertilizer use efficiency?); identifying cost-effective, enforceable, and scalable ways to implement a potential CSA precondition requirement for ISPs; and comparing the costeffectiveness of such a requirement to that of other approaches to promote CSA. Given the very mixed results of ISPs, the rampant elite capture and diversion of inputs intended for the programs, and the high price tag and opportunity cost of ISPs in general and in relation to other programs and investments to develop and stimulate uptake of CSA technologies (see Jayne and Rashid 2013; Lunduka et al. 2013; Mason et al. 2013; among many others), linking CSA promotion to ISPs may be a risky proposition.

\subsection{Concluding Remarks}

There are three overarching challenges to be addressed for ISPs to effectively contribute to CSA objectives. First is the limited understanding of workable approaches for internalizing the externalities associated with GHG-emitting land management decisions of millions of resource-poor farmers in developing countries. This is a problem for social scientists to resolve by developing ways for carbon markets to be linked to smallholders in Africa and that can provide farmers monetary incentives for the adoption of particular GHG mitigating practices, may be a viable strategy for achieving widespread farm management change, but much remains to be worked out before viable programs could be implemented in most of sub-Saharan Africa.

The second challenge is the currently limited on-shelf technologies and management know-how to improve smallholder yield stability and growth in the face of 
increasing climate variability. Most on-shelf technologies and practices being promoted as being "climate smart" appear to help at the margin, but cannot be relied upon to meaningfully stabilize harvests in the face of major droughts or floods or to arrest the degree of distress migration often associated with it. More effective water and soil fertility management techniques appropriate for the situation of lowresource farmers are needed, and this will requires significantly increased investment in localized, adaptive research for the wide range of smallholder farming systems in sub-Saharan Africa. This is a challenge both for the scientific research community and for policy makers to make the necessary long-term funding commitments to adaptive agricultural research and development programs.

The third challenge is the near absence of effective bi-directional learning and extension systems to help farmers profitably adopt and adapt proven farm management practices. This again presents challenges for policy makers to make the necessary long-term funding commitments and to social scientists to design extension systems that effectively link scientists and farmers disaggregated by particular agroecologies and degrees of resource constraints.

Addressing these three challenges is a tall order. For this reason, we believe that much greater progress is needed in each of these three areas before it could be practical or effective to try to use ISPs as a vehicle to make agriculture more climatesmart. This conclusion is not meant to stifle progress where progress can be made, but is rather to point out the scope of the challenges before us. It will take time for the proposals made here to generate meaningful impacts. This is why there is no time to waste in getting started.

\section{Appendix 1: Estimating the Contribution of Increased Fertilizer Use to Greenhouse Gas Emissions}

African countries contribute to climate change through emissions of greenhouse gases from agriculture, forestry and land use (AFoLU). As much as one third of all emissions globally are from AFoLU, but in many African countries these emission sources constitute the major components of their national GHG inventories, rather than the industrial or energy sectors. For instance, in Malawi 80\% of national GHG emissions are from forestry and agriculture, although the absolute contribution to global greenhouse gas emissions is tiny. As a result of the Paris Agreements of the United Nations Framework Convention on Climate Change (UNFCCC) African countries are developing means and measures to mitigate these emissions through actions in the AFoLU sectors, including reducing emissions from deforestation and forest degradation, conservation of carbon stocks in forests and agricultural soils, improved management of agricultural waste and other interventions. In spite of actions to reduce emissions, agriculture and forestry will surely be impacted by climate change. As such, many African countries are taking a broad view and are also implementing adaptation strategies. 
National climate action strategies are being developed by all African Countries through the process of the Nationally Determined Contributions, or NDC, which is the main reporting instrument that is the focal point for each country's international commitments. Climate Smart Agriculture (CSA) is being viewed as one model for adaptation. This model focuses on developing interventions in traditional practices that can increase resilience of agricultural systems to adverse effects of climate change and which can be promulgated at the national level and applied locally at farm scale. One compelling intervention under the CSA model is the national subsidy programs for inorganic fertilizers. Increasing the availability and application of chemical fertilizers is seen as a means to increase crop productivity and provide enhanced fertility to nutrient-poor soils, and buffer adverse effects of drought and other climate impacts.

However, at the same time that these measures provide apparent benefits from an adaptation point of view, the use of inorganic fertilizers also increases GHG emissions in agricultural soils, particularly for non-carbon GHGs such as nitrous oxide $\left(\mathrm{N}_{2} 0\right)$. Using estimation methods defined by the Intergovernmental Panel on Climate Change (IPCC 2006), the FAO (FAO 2014) has published estimates of national emissions from agricultural inputs for many African countries. GHG emissions from the application of synthetic fertilizers has increased $25 \%$ between 2000 and 2014 , from $16,000 \mathrm{GgCO} 2$ e to $20,000 \mathrm{GgCO} 2 \mathrm{e}$, representing about $3 \%$ of the total emissions from all agricultural practices, including land clearing. However there is considerable variation across Africa, with a trend toward higher proportional emissions from fertilizers in poorer countries. For instance, in Nigeria where other inputs and energy contributed more to agriculture than in most countries, only about $1.2 \%$ of the total emissions from agriculture are attributed to fertilizer applications on soils in 2012, while in Malawi as much as $18 \%$ of total agricultural emissions are attributed to fertilizer applications in 2012. In Zambia the proportion is 4\%, while in Kenya it is $2 \%$ for 2012.

For the most part these are relatively low emissions compared to other components of the agriculture production system; however subsidy programs are expected to raise fertilizer use, particularly for poorer countries such as Malawi. These emissions of GHG, especially non-carbon GHG such as $\mathrm{N}_{2} 0$, represent the negative impacts of measures involving increased use of fertilizer to improve resilience of agricultural soils and plant productivity. Thus, interventions that may have positive influence on adaptation may have outcomes that negatively offset gains in mitigation efforts. For instance, annual emission rates of GHG from fertilizer use in agriculture in Malawi is approximately equivalent to protecting 500 hectares of Miombo woodland from deforestation. The exact magnitude of the offset depends on a complex array of factors that are not being studied, including the type of fertilizer used, fertilizer application rates and timing, influence of episodic events that may be changing with climate changes such as severe rain events, soil conditions and land management.

Most studies, and the IPCC (2006), estimate $\mathrm{N}$ emission factors for $\mathrm{N}_{2} \mathrm{O}$ to be between $1 \%$ and $3 \%$ of the nitrogen nutrient in fertilizers. Thus, we can estimate the approximate GHG emissions associated with the application of fertilizer under sub- 
sidy programs. We assume an application of 300,000 metric tons of fertilizer, of which half is in the form of urea with $50 \% \mathrm{~N}$ and half in the form of inorganic NPK with $30 \% \mathrm{~N}$. This would equate to roughly 45,000 metric tons of $\mathrm{N}$ from NPK fertilizer and 75,000 metric tons of $\mathrm{N}$ from urea. Using IPCC emission factors for $\mathrm{N}_{2} 0$ emissions this would result in 1200-3600 metric tons of $\mathrm{N}_{2} \mathrm{O}$ per ton of $\mathrm{N}$, which when converted to units of nitrous oxide (multiplied by 44/28) and then to carbon dioxide equivalents using a greenhouse warming potential (GWP) of 300 would be $565,714-1,697,143$ metric tons of $\mathrm{CO}_{2}$ equivalent $\left(\mathrm{CO}_{2} \mathrm{e}\right)$ greenhouse gas emission. Using IPCC emission factors for urea, we estimate an additional 30,000 metric tons of CO2e. Thus, the total emissions from the application of 300,000 tons of fertilizer of the type we used to make our estimate would be 595,714-1,727,143 metric tons $\mathrm{CO}_{2}$ e per year.

The contributions of inorganic fertilizer to adaption and agricultural resilience would come at a cost to efforts to mitigate emissions from deforestation and degradation; the additional emissions from fertilizer applications would be a significant new emission source and would counter efforts to mitigate emissions in the AFoLU sector.

These estimates are for field applications of inorganic fertilizers. The demand for fertilizer would stimulate production of fertilizers and this production system also produces GHGs, mostly from the large use of energy which are typically from fossil fuels. Although most carbon GHG accounting methods do not attribute production emissions to the end-use emissions, and keep these accounts separate, for the sake of illustration we estimate the additional contribution of producing and transporting 300,000 t of inorganic fertilizer. Several studies suggest an emission factor for fertilizer production to be 2.5-5.67 metric tons of $\mathrm{CO}_{2}$ e per metric ton of fertilizer produced (Kool et al. 2012). Thus, a basic estimate of the magnitude of the emissions associated with the 300,000 additional tons of fertilizer production would be $750,000-1,701,000$ metric tons of $\mathrm{CO}_{2} \mathrm{e}$.

Combining both agricultural field emissions with emissions associated with production, we estimate that 300,000 tons of additional fertilizer manufacture and use would result in GHG emissions of between 1,345,714 and 3,428,143 metric tons of $\mathrm{CO}_{2}$ equivalent. Approximately $55 \%$ of these emissions are attributed to the industrial production of fertilizers (which we believe are conservative estimates). These estimates would represent an increase in fertilizer emission of approximately $10 \%$, and would represent an emission that counter offsets approximately 120,000 to 300,000 hectares of reforestation in mitigation projects.

\section{References}

Arslan, A., N. McCarthy, L. Lipper, S. Asfaw, A. Cattaneo, and M. Kokwe. 2015. "Climate Smart Agriculture? Assessing the Adaptation Implications in Zambia." Journal of Agricultural Economics doi: 10.1111/1477-9552.12107

Branca, G., McCarthy, N., Lipper, L., \& Jolejole, M. C. (2011). Climate-smart agriculture: a synthesis of empirical evidence of food security and mitigation benefits from improved cropland management. Mitigation of climate change in agriculture series, 3, 1-42. 
Burke, W.J. 2012. "Determinants of Maize Yield Response to Fertilizer Application in Zambia: Implications for Strategies to Promote Smallholder Productivity." PhD dissertation, Michigan State University.

Byerlee, D., J. Stephenson, and N. Villoria. 2014. Does intensification slow crop land expansion or encourage deforestation? Global Food Security (3), 92-98.

Campbell, B.M., P. Thornton, R. Zougmoré, P. van Asten, and L. Lipper. 2014. "Sustainable Intensification: What is its Role in Climate Smart Agriculture?" Current Opinion in Environmental Sustainability 8: 39-43.

Carter, M. R., \& Rennie, D. A. (1982). Changes in soil quality under zero tillage farming systems: distribution of microbial biomass and mineralizable $\mathrm{C}$ and $\mathrm{N}$ potentials. Canadian Journal of Soil Science, 62(4), 587-597.

Carter, D. C., D. Harris, J. B. Youngquist, and N. Persaud. "Soil properties, crop water use and cereal yields in Botswana after additions of mulch and manure." Field Crops Research 30, no. 1-2 (1992): 97-109.

Chibwana, C., M. Fisher, and G. Shively. 2012. "Cropland Allocation Effects of Agricultural Input Subsidies in Malawi." World Development 40(1):124-133.

Chibwana, C., G. Shively, M. Fisher, and C. Jumbe. 2014. "Measuring the Impacts of Malawi's Farm Input Subsidy Programme." African Journal of Agriculture and Resource Economics 9(2):132-147.

Chivenge, P. P., Murwira, H. K., Giller, K. E., Mapfumo, P., \& Six, J. (2007). Long-term impact of reduced tillage and residue management on soil carbon stabilization: Implications for conservation agriculture on contrasting soils.Soil and Tillage Research, 94(2), 328-337.

Dalal, R. C., Henderson, P. A., \& Glasby, J. M. (1991). Organic matter and microbial biomass in a vertisol after $20 \mathrm{yr}$ of zero-tillage. Soil Biology and Biochemistry 23(5), 435-441.

Doran, J. W. (1980). Soil microbial and biochemical changes associated with reduced tillage. Soil Science Society of America Journal, 44(4), 765-771.

Drinkwater, L. E., \& Snapp, S. S. (2007). Nutrients in agroecosystems: rethinking the management paradigm. Advances in Agronomy, 92, 163-186.

Engel, S., \& Muller, A. (2016). Payments for Environmental Services to Promote Climate-Smart Agriculture? Potential and Challenges. Potential and Challenges (January 22016 ).

Food and Agricultural Organization. 2010. Climate-Smart Agriculture: Policies, Practices and Financing for Food Security, Adaptation and Mitigation, Rome., http://www.fao.org/ docrep/013/i1881e/i1881e00.pdf

FAO. 2013. Climate-Smart Agriculture Sourcebook. Rome, Italy: FAO.

FAO 2014. Agriculture, Forestry and Other Land Use Emissions by Sources and Removals by Sinks. Working Paper ESS/14-02. Food and Agriculture Organization, United Nations, Rome. Wood, S. and A. Cowie 2004. A Review of Greenhouse Gas Emission Factors for Fertilizer Production, Research and Development Division, State Forests of New South Wales. Cooperative Research Centre for Greenhouse Accounting. For IEA Bioenergy Task 38

Grainger-Jones, E. (2011). Climate-smart smallholder agriculture: What's different. IFAD Occasional paper, 3 .

Fernández-Ugalde, O., Virto, I., Bescansa, P., Imaz, M. J., Enrique, A., \& Karlen, D. L. (2009). No-tillage improvement of soil physical quality in calcareous, degradation-prone, semiarid soils. Soil and Tillage Research,106(1) 29-35.

Govaerts, B., Sayre, K. D., \& Deckers, J. (2005). Stable high yields with zero tillage and permanent bed planting?. Field crops research, 94(1), 33-42.

Hernanz, J. L., López, R., Navarrete, L., \& Sanchez-Giron, V. (2002). Long-term effects of tillage systems and rotations on soil structural stability and organic carbon stratification in semiarid central Spain. Soil and Tillage Research, 66(2), 129-141.

Hertel, T. W. (2011). The global supply and demand for agricultural land in 2050: A perfect storm in the making?. American Journal of Agricultural Economics, 93(2), 259-275.

Holden, S., and R. Lunduka. 2010. "Too Poor to be Efficient? Impacts of the Targeted Fertilizer Subsidy Programme in Malawi on Farm Plot Level Input Use, Crop Choice and 
Land Productivity." Noragric Report No. 55, Department of International Environment and Development Studies, Norwegian University of Life Sciences, Ås, Norway.

Holden, S., and R. Lunduka. 2012. "Do Fertilizer Subsidies Crowd Out Organic Manures? The Case of Malawi." Agricultural Economics 43(3):303-314.

IPCC (Intergovernmental Panel on Climate Change) 2006. 2006 IPCC Guidelines for National Greenhouse Gas Inventories, Volume 4: Agriculture, Forestry and Other Land Use. UNFCCC, Geneva.

IPCC (Intergovernmental Panel on Climate Change) 2014. Mitigation of Climate Change. Contribution of Working Group III to the Fifth Assessment Report of the Intergovernmental Panel on Climate Change [Edenhofer, O., R. Pichs-Madruga, Y. Sokona, E. Farahani, S. Kadner, K. Seyboth, A. Adler, I. Baum, S. Brunner, P. Eickemeier, B. Kriemann, J. Savolainen, S. Schlömer, C. von Stechow, T. Zwickel and J.C. Minx (eds.)]. Cambridge University Press, Cambridge, United Kingdom and New York, NY, USA.

Jayne, T.S., and S. Rashid. 2013. "Input Subsidy Programs in Sub-Saharan Africa: A Synthesis of Recent Evidence.” Agricultural Economics 44(6):547-562.

Jayne, T., N. Mason, W. Burke, and J. Ariga. Forthcoming. Input Subsidy Programs in Africa: A Review of Recent Experience. Policy Brief, Food Security Group, Michigan State University, East Lansing.

Karamba, R.W. 2013. "Input Subsidies and Their Effect on Cropland Allocation, Agricultural Productivity, and Child Nutrition: Evidence from Malawi." PhD dissertation, American University.

Kaczan, D., Arslan, A., \& Lipper, L. (2013). Climate-smart agriculture. A review of current practice of agroforestry and conservation agriculture in Malawi and Zambia ESA working paper, (13-07).

Kool, A., M. Marinussen, H. Blonk. 2012. LCI Data for the Calculation Tool Feedprint for Greenhouse Gas Emissions of feed production and Utilization: GHG Emissions of N,P and K Fertilizer Production, Blonk Consultants, Gouda, Netherlands.

Lal, R. (2006). Enhancing crop yields in the developing countries through restoration of the soil organic carbon pool in agricultural lands. Land Degradation \& Development, 17(2), 197-209.

Lawry, S., Samii, C., Hall, R., Leopold, A., Hornby, D., \& Mtero, F. (2014). The impact of land property rights interventions on investment and agricultural productivity in developing countries: a systematic review.Campbell Systematic Reviews, 10(1).

Levine, N.K. 2015. "Do Input Subsidies Crowd In or Crowd Out Other Soil Fertility Management Practices? Evidence from Zambia.” MS Plan B Paper, Michigan State University. Available at http:// web2.msue.msu.edu/afreTheses/fulltext/N.\%20Kendra\%20Levine-\%20Final\%20Plan\%20B\%20 Paper.pdf.

Lipper, L. and D. Zilberman. Forthcoming. Climate Smart Agriculture: Introduction, in D. Zilberman, L. Lipper, S. Asfaw, D. Cattaneo (eds) FAO book on climate change.

Lipper, L., Thornton, P., Campbell, B. M., Baedeker, T., Braimoh, A., Bwalya, M., and Hottle, R. (2014). Climate-smart agriculture for food security. Nature Climate Change, 4(12), 1068-1072.

Logistics Unit. 2015. Final Report on the Implementation of the Agricultural Inputs Subsidy Programme 2014-15. Lilongwe, Malawi: Logistics Unit.

Lunduka, R., J. Ricker-Gilbert, and M. Fisher. 2013. "What are the Farm-Level Impacts of Malawi's Farm Input Subsidy Program? A Critical Review.” Agricultural Economics 44(6):563-579.

Marenya, P., and C. Barrett. 2009. "State-Conditional Fertilizer Yield Response on Western Kenyan Farms." Am. J. Agr. Econ. 91(4):991-1006.

Marenya, P., E. Nkonya, W. Xiong, J. Deustua, and E. Kato. 2012. "Which policy would work better for improved soil fertility management in sub-Saharan Africa, feritilzer subsidies or carbon credits?" Agricultural Systems 110: 162-172.

Marenya, P., V. H. Smith, and E. Nkonya. 2014. "Relative preferences for soil conservation incentives among smallholder farmers: evidence from Malawi.” American Journal of Agricultural Economics 96 (3): 690-710.

Mason, N. M., Wineman, A., Kirimi, L., \& Mather, D. (2015). The effects of Kenya's 'smarter' input subsidy program on crop production, incomes, and poverty. Tegemeo Institute Policy Brief 11. 
Mason, N. M., \& Ricker-Gilbert, J. (2013). Disrupting demand for commercial seed: Input subsidies in Malawi and Zambia. World Development, 45, 75-91.

Mason, N.M., T.S. Jayne, and R. Mofya-Mukuka. 2013. "Zambia's Input Subsidy Programs." Agricultural Economics 44(6):613-628.

Mbagwu, J. S. (1991). Mulching an ultisol in southern Nigeria: effects on physical properties and maize and cowpea yields. Journal of the Science of Food and Agriculture, 57(4), 517-526.

McCarthy, N., Lipper, L., \& Branca, G. (2011). Climate-smart agriculture: smallholder adoption and implications for climate change adaptation and mitigation. Mitigation of Climate Change in Agriculture Working Paper, 3, 1-37.

Meinzen-Dick, R., Bernier, Q., \& Haglund, E. (2013). The Six 'ins' of Climate-Smart Agriculture: Inclusive Institutions for Information, Innovation, Investment and Insurance (No. 114). International Food Policy Research Institute (IFPRI).

Namonje-Kapembwa, T., T.S. Jayne, and R. Black. 2015. "Does Late Delivery of Subsidized Fertilizer Affect Smallholder Maize Productivity and Production?" Selected paper presented at the Agricultural and Applied Economics Association and Western Agricultural Economics Association Annual Meeting, San Francisco, CA 26-28 July.

Pan, L., and L. Christiaensen. 2012. Who is Vouching for the Input Voucher? Decentralized Targeting and Elite Capture in Tanzania. World Development 40(8):1619-1633.

Paul, B. K., Vanlauwe, B., Ayuke, F., Gassner, A., Hoogmoed, M., Hurisso, T. T., \& Pulleman, M. M. (2013). Medium-term impact of tillage and residue management on soil aggregate stability, soil carbon and crop productivity. Agriculture, ecosystems \& environment, 164, 14-22.

Powlson, D. S., Stirling, C. M., Thierfelder, C., White, R. P., \& Jat, M. L. (2016). Does conservation agriculture deliver climate change mitigation through soil carbon sequestration in tropical agro-ecosystems? Agriculture, Ecosystems \& Environment 220, 164-174.

Raimbault, B. A., \& Vyn, T. J. (1991). Crop rotation and tillage effects on corn growth and soil structural stability. Agronomy Journal, 83(6), 979-985.

Ricker-Gilbert, J., Jayne, T. S., \& Chirwa, E. (2011). Subsidies and crowding out: A double-hurdle model of fertilizer demand in Malawi. American Journal of Agricultural Economics, aaq122.

Robertson, G. P., \& Swinton, S. M. (2005). Reconciling agricultural productivity and environmental integrity: a grand challenge for agriculture. Frontiers in Ecology and the Environment, 3(1), 38-46.

Rusinamhodzi, L., Corbeels, M., van Wijk, M. T., Rufino, M. C., Nyamangara, J., \& Giller, K. E. (2011). A meta-analysis of long-term effects of conservation agriculture on maize grain yield under rainfed conditions. agronomy for sustainable development, 31(4), 657-673.

Sisti, C. P., dos Santos, H. P., Kohhann, R., Alves, B. J., Urquiaga, S., \& Boddey, R. M. (2004). Change in carbon and nitrogen stocks in soil under 13 years of conventional or zero tillage in southern Brazil. Soil and tillage research, 76(1), 39-58.

Sitko, N. J., Chamberlin, J., \& Hichaambwa, M. (2014). Does smallholder land titling facilitate agricultural growth?: An analysis of the determinants and effects of smallholder land titling in Zambia. World Development, 64, 791-802.

Sitko, N. J., Bwalya, R., Kamwanga, J., \& Wamulume, M. (2012). Assessing the feasibility of implementing the Farmer Input Support Programme (FISP) through an electronic voucher system in Zambia (No. 123210). Michigan State University, Department of Agricultural, Food, and Resource Economics.

Snapp, S., M. Blackie, R. Gilbert, R. Bezner-Kerr, G. Kanyama-Phiri. 2010. Biodiversity can support a greener revolution in Africa. Proceedings of National Academy of Science, 10720840 20845. Doi: 10.1073/pnas.1007199107.

Snapp, S., Jayne, T.S., Mhango, W., Ricker-Gilbert, J., \& Benson, T. (2014). "Maize yield response to nitrogen in Malawi's smallholder production systems." Working Paper No. 9, Malawi Strategy Support Program. International Food Policy Research Institute.

Snyder, C.S., T.W. Bruulsema, T.L. Jensen, P.E. Fixen. 2009. Review of greenhouse gas emissions from crop production systems and fertilizer management effects, Agriculture, Ecosystems \& Environment 133, (3-4): 247-266 
Tittonell, P., \& Giller, K. E. (2013). When yield gaps are poverty traps: the paradigm of ecological intensification in African smallholder agriculture. Field Crops Research, 143, 76-90.

Triplett, G. B., Van Doren, D. M., \& Schmidt, B. L. (1968). Effect of corn (Zea mays L.) stover mulch on no-tillage corn yield and water infiltration. Agronomy Journal, 60(2) 236-239.

Vondolia, G.K., H. Eggert, and J. Stage. 2012. "Nudging Boserup? The Impact of Fertilizer Subsidies on Investment in Soil and Water Conservation." Discussion Paper No. 12-08, Environment for Development and Resources for the Future, Washington, DC.

World Bank. 2011. Policy brief: Opportunities and challenges for climate-smart agriculture in Africa. Washington, D.C.: World Bank.

Xu, Z., Z. Guan, T.S. Jayne, and R. Black. 2009. "Factors Influencing the Profitability of Fertilizer Use on Maize in Zambia." Agricultural Economics 40(4):437-446.

You, L., Ringler, C., Wood-Sichra, U., Robertson, R., Wood, S., Zhou, T., Nelson, G. 2012. What Is the Irrigation Potential for Africa? A Combined Biophysical and Socioeconomic Approach. Food Policy 36, 770-782.

ZMAL (Zambia Ministry of Agriculture and Livestock). 2015a. Farmer Input Support Programme Implementation Manual 2015/16 Agricultural Season. Lusaka, Zambia: ZMAL.

ZMAL. 2015b. Farmer Input Support Programme Electronic Voucher Implementation Manual 2015/16 Agricultural Season. Lusaka, Zambia: ZMAL.

Open Access This chapter is distributed under the terms of the Creative Commons AttributionNonCommercial-ShareAlike 3.0 IGO license (https://creativecommons.org/licenses/by-nc-sa/3.0/ igo/), which permits any noncommercial use, duplication, adaptation, distribution, and reproduction in any medium or format, as long as you give appropriate credit to the Food and Agriculture Organization of the United Nations (FAO), provide a link to the Creative Commons license and indicate if changes were made. If you remix, transform, or build upon this book or a part thereof, you must distribute your contributions under the same license as the original. Any dispute related to the use of the works of the FAO that cannot be settled amicably shall be submitted to arbitration pursuant to the UNCITRAL rules. The use of the FAO's name for any purpose other than for attribution, and the use of the FAO's logo, shall be subject to a separate written license agreement between the FAO and the user and is not authorized as part of this CC-IGO license. Note that the link provided above includes additional terms and conditions of the license.

The images or other third party material in this chapter are included in the chapter's Creative Commons license, unless indicated otherwise in a credit line to the material. If material is not included in the chapter's Creative Commons license and your intended use is not permitted by statutory regulation or exceeds the permitted use, you will need to obtain permission directly from the copyright holder. 